NASA Technical Memorandum 106106

\title{
Atomizing-Gas Temperature Effect on Cryogenic Spray Dropsize
}

Robert D. Ingebo

Lewis Research Center

Cleveland, Ohio

Prepared for the

29th Joint Propulsion Conference and Exhibit cosponsored by the AIAA, SAE, ASME, and ASEE Monterey, California, June 28-30, 1993 


\title{
ATOMIZING-GAS TEMPERATURE EFFECT ON CRYOGENIC SPRAY DROPSIZE
}

\author{
Robert D. Ingebo \\ National Aeronautics and Space Administration \\ Lewis Research Center \\ Cleveland, Ohio 44135
}

\section{Abstract}

Correlating expressions for two-phase flow breakup of liquid nitrogen, $\mathrm{LN}_{2}$, jets in sonic velocity nitrogen gasflows were obtained for an atomizing-gas temperature range of 111 to $442 \mathrm{~K}$. The correlations were based on characteristic dropsize measurements obtained with a scattered-light scanner. The effect of droplet vaporization on the measurements of the volume-median dropsize, $D_{\mathrm{v} .5}$, was calculated by using previously determined heat and momentum transfer expressions for droplets evaporating in high-velocity gasflow. Finally, the dropsize of the originally unvaporized spray, $D_{v .5 c}$, was calculated, normalized with respect to jet diameter, $D_{0}$, and correlated with atomizing-gas flowrate and temperature, according to the following expression:

$$
\frac{\mathrm{D}_{\mathrm{o}}}{\mathrm{D}_{\mathrm{v} .5 \mathrm{c}}}=9.0\left(\mathrm{We} \operatorname{Re} \frac{\rho_{\mathrm{g}}}{\rho_{1}}\right)^{0.44}\left(\frac{\mathrm{t}_{\mathrm{g}}}{\mathrm{t}_{\mathrm{o}}}\right)^{1.25}
$$

where $\mathrm{WeRe}=\rho_{\mathrm{g}}^{2} \mathrm{D}_{\mathrm{o}}^{2} \mathrm{~V}_{\mathrm{c}}^{3} / \mu_{1} \sigma$. Here $\mu_{1}$ is liquid viscosity, $\rho_{\mathrm{g}}$ and $\rho_{1}$ are gas and liquid densities, respectively, $\sigma$ is surface tension, $V_{c}$ is acoustic gas velocity and $T_{g}$ is atomizing-gas temperature, normalized with respect to airstream temperature, $\mathrm{T}_{\mathrm{o}}=293 \mathrm{~K}$. This expression agrees well with atomization theory which predicts $\mathrm{D}_{\mathrm{v} .5} \sim \mathrm{V}_{\mathrm{c}}^{1.33}$, for liquid-jet breakup in high-velocity gasflow.

\section{Nomenclature}

A fuel nozzle orifice area, $\mathrm{cm}^{2}$

a acceleration, $\mathrm{cm} / \mathrm{sec}^{2}$

$\mathrm{C}_{\mathrm{d}}$ drag coefficient

$\mathrm{D}_{\mathrm{o}}$ liquid-jet diameter, $\mathrm{cm}$

$\mathrm{D}_{\mathrm{v} .5}$ volume median drop diameter, $\mathrm{cm}$

k correlation coefficient for Eq. (1)

$\mathbf{k}^{\prime} \quad$ correlation coefficient for Eq. (6)

$\mathrm{k}^{\prime \prime} \quad$ correlation coefficient for Eq. (7)

$\mathrm{Nu}$ heat-transfer Nusselt number, based on $D_{\mathrm{v} .5 \mathrm{e}}$

n exponent for Eq. (1)

$\begin{array}{ll}\text { Re } & \text { Reynolds number based on } \mathrm{D}_{\mathrm{v} .5 \mathrm{e}} \\ \mathrm{t} & \text { vaporization time, } \mathrm{sec} \\ \mathrm{V}_{\mathrm{c}} & \text { acoustic velocity, } \mathrm{cm} / \mathrm{sec} \\ \mathrm{W} & \text { weight flow of fluid, } \mathrm{g} / \mathrm{sec} \\ \mathrm{We} & \text { Weber number based on } \mathrm{D}_{\mathrm{v} .5 \mathrm{e}} \\ \mathrm{x} & \text { axial downstream spray sampling distance } \\ \sigma & \text { surface tension relative to air, dynes } / \mathrm{cm} \\ \mu & \text { absolute viscosity, } \mathrm{g} / \mathrm{cm} \mathrm{sec} \\ \rho & \text { fluid density, } \mathrm{g} / \mathrm{cm}^{3}\end{array}$

\section{Subscripts}

$\begin{array}{ll}\text { c } & \text { calculated } \\ \text { d } & \text { droplet } \\ \text { e } & \text { experimental } \\ \text { f } & \text { free-stream } \\ \text { g } & \text { gaseous nitrogen, } \mathrm{GN}_{2} \\ \text { l } & \text { liquid nitrogen, } \mathrm{LN}_{2} \\ \text { o } & \text { orifice }\end{array}$

\section{Introduction}

An experimental investigation of cryogenic liquidjet breakup in high-velocity gasflow was conducted to determine the effect of atomizing-gas temperature, $T_{g}$, on characteristic dropsize, $D_{\mathbf{v} .5}$, of liquid-nitrogen sprays. Very little data are available in the spray literature that show gas-temperature effects on atomization. However, the effect of gas velocity, $V_{g}$, on liquid-jet breakup in gas streams has been studied by numerous investigators. ${ }^{1-7}$ Their results are summarized in Table I. Water-jet breakup results described in Ref. 1 show that good agreement can be obtained with atomization theory, when dropsize measurements are made close to the atomizer orifice. However, a marked effect of droplet vaporization on dropsize measurements of water sprays did occur, as reported in Ref. 1, when the sampling distance downstream of the atomizer was increased from 2.2 to $6.7 \mathrm{~cm}$. In the case of liquid-nitrogen sprays, good agreement with atomization theory may not occur, since highly volatile sprays can quickly become partially vaporized. 
In a previous investigation of disintegrating $\mathrm{LN}_{2}$ jets ${ }^{2}$ dropsize measurements were made in the presence of relatively high thermal gradients. The atomizing gas, $\mathrm{GN}_{2}$, was at room temperature, $293 \mathrm{~K}$, whereas $\mathrm{LN}_{2}$ droplet temperatures were near the boiling point of $\mathrm{LN}_{2}$, $77 \mathrm{~K}$. Thus, heat transfer across the gas film had a driving potential, $\Delta \mathrm{T}$, of $216 \mathrm{~K}$. This is considerably higher than values of $\Delta \mathrm{T}$ in the order of 10 to $15 \mathrm{~K}$, which were encountered in previous water spray studies reported in Ref. 1.

Although the original characteristic dropsize initially formed at the atomizer orifice was not measured directly, in the present study, it was possible to determine the initial value of $\mathrm{D}_{\mathrm{v} .5 \mathrm{c}}$ by calculating the amount it had changed due to evaporation. Droplet acceleration and vaporization rates were calculated from heat transfer and drag coefficient data given in Ref. 8. These data had previously been obtained for drops accelerating and vaporizing in high-velocity gasflows. Such data are difficult to obtain for drops that are microscopic in size and attain high velocity in a short distance of travel. By using heat transfer and drag coefficients given in Ref. 8, values of $\Delta D_{\mathrm{v} .5}$ produced by droplet vaporization could be calculated and used to determine original values of $\mathrm{D}_{\mathrm{v} .5 \mathrm{c}}$, that existed before vaporization and occurred.

To determine the effect of atomizing-gas temperature and gas mass-flux on spray dropsize produced by liquid-jet breakup in high-velocity gasflow, the characteristic dropsize $D_{\mathbf{v} .5 e}$ was measured with a scatteredlight scanner developed at NASA Lewis Research Center by Buchele. ${ }^{9}$ Sprays were sampled with the laser beam center line positioned at a distance of $1.2 \mathrm{~cm}$ downstream of the fuel nozzle orifice to minimize the loss of small droplets due to vaporization. Volume mean diameter, $D_{\mathrm{v} .5 \mathrm{e}}$ varied from 3 to $30 \mu \mathrm{m}$ and measurements of $D_{v .5 e}$ were made at atomizing-gas temperatures of 111 , 293 , and $422 \mathrm{~K}$, respectively.

\section{Apparatus and Procedure}

A two-fluid nozzle was used with assist nitrogen gasflow, $\mathrm{GN}_{2}$, to breakup liquid nitrogen, $\mathrm{LN}_{2}$-jets, as shown in Fig. 1. It was mounted at the center line of the 24-cm diameter duct and operated over pressure ranges of 0.2 to $1.0 \mathrm{MPa}$ for both $\mathrm{LN}_{2}$ and $\mathrm{GN}_{2} . \mathrm{LN}_{2}$ sprays were injected downstream into the airflow, just upstream of the duct exit, and sampled at a distance of $1.2 \mathrm{~cm}$ downstream from the atomizer orifice to the center line of the $4.4 \times 1.9 \mathrm{~cm}$ laser beam. The two-fluid nozzle was fabricated according to the diagram illustrated in Fig. 2. $\mathrm{LN}_{2}$ at a temperature of $77 \mathrm{~K}$ was axially injected into the airstream by gradually opening the control valve until the desired flowrate of $51 \mathrm{~g} / \mathrm{sec}$ was obtained as indicated by a turbine flowmeter. The atomizing gas was then turned on and weight flowrate was measured with a $0.51-\mathrm{cm}$ diameter sharp-edge orifice. After the air, $\mathrm{GN}_{2}$ and $\mathrm{LN}_{2}$ flowrates were set, the volume median diameter, $D_{v .5 e}$, was measured with the scattered-light scanner.

The optical system of the scattered-light scanner shown in Fig. 3 consisted of a laser beam expander with spatial filter, rotating scanning-slit and a detector. The instrument measures scattered light as a function of scattering angle by repeatedly sweeping a variablelength slit in the focal plane of the collecting lens. The data obtained is scattered-light energy as a function of the scattering angle relative to the laser beam axis. This method of particle size measurement is similar to that described in Ref. 10. Measurements of scattered-light energy normalized by the maximum energy were plotted against scattering angle and used to determine volumemedian diameter, $\mathrm{D}_{\mathbf{v} .5 \mathrm{e}}$, as described in Ref. 11. Also, it should be noted that the size-distribution dispersion can also be determined from this plot. Also, this method of determining characteristic dropsize and dispersion of dropsize can be used independent of particle size distribution function, according to Buchele. ${ }^{11}$ For a typical measurement, the scan is repeated 60 times per second to average out any temporal variations in the energy curve.

Spray pattern effects were minimized by measuring $D_{v .5 e}$ for the entire cloud of droplets. The instrument was calibrated with five sets of monosized polystyrene spheres having diameters of $8,12,25,50$, and $100 \mu \mathrm{m}$. Since the sprays were sampled very close to the atomizer orifice, they contained a relatively high number-density of very small droplets. As a result, the light-scattering measurements required correction for multiple scattering as described in Ref. 12. Also, dropsize measurements were corrected to include Mie scattering theory when very small drop diameters, i.e., $10 \mu \mathrm{m}$, were measured. Reproducibility tests showed that experimental measurements agreed within \pm 5 percent.

It was necessary to correct experimental measurements by taking background readings when the atomizing-gas, $\mathrm{GN}_{2}$ temperature was well above or below airstream temperature. This was due to high gasdensity gradients being present when atomizing-gas temperatures were relatively high, $422 \mathrm{~K}$, or low, $111 \mathrm{~K}$, as compared with the surrounding airstream temperature of $293 \mathrm{~K}$. Only a small correction was needed at $\mathrm{T}_{\mathrm{g}}=293 \mathrm{~K}$, since gas density gradients were close to zero. Temperature gradients for nitrogen vapor films surrounding the droplets were assumed to have negligible effect on measurements, since this was found to be the case when water sprays were studied in Ref. 15. 


\section{Experimental Results}

To obtain dropsize measurements, the entire $\mathrm{LN}_{2}$ spray cross section was sampled and the laser beam center line was located at a distance of $1.2 \mathrm{~cm}$ downstream of the fuel-nozzle orifice, as shown in Fig. 1. Droplets traveled a distance of $2.0 \mathrm{~cm}$ in passing through the scattered-light scanner laser beam. However, some of the very small and highly volatile $\mathrm{LN}_{2}$ droplets were completely vaporized before they could travel through the laser beam. As a result, experimental values of $\mathrm{D}_{\mathrm{v} .5 \mathrm{e}}$ were obtained for partially vaporized sprays. Thus, it was necessary to calculate the change in dropsize, $\Delta D_{v .5}^{2}$, in order to estimate the initially unvaporized spray dropsize, $D_{\mathrm{v} .5 \mathrm{c}}$, that was formed at the fuel-nozzle orifice. Values of $D_{v .5 c}$, were then correlated with atomizing-gas flowrate, $W_{g}$. Such correlations are needed for modeling spray vaporization and combustion processes.

\section{Effect of GN 2 Flowrate on $\mathrm{D}_{\mathrm{v} .5 \mathrm{e}}$}

Measurements of $\mathrm{D}_{\mathrm{y} .5 \mathrm{e}}$ were made with the scattered-light scanner and plotted against $\mathrm{GN}_{2}$ flowrate, $W_{g}$, as shown in Fig. 4. Since high-velocity atomizing-gas flowrates were used, cryogenic liquid-jet breakup occurred primarily in the regime of aerodynamic stripping. No indication of secondary breakup of droplets was observed since low atomizing-gas velocities were not used. Thus, the low gas-velocity regime of capillary wave breakup of liquid jets was not investigated.

From the plot shown in Fig. 4, reciprocal $D_{\text {v.5e }}$ was correlated with atomizing-gas flowrate, $\mathrm{W}_{\mathrm{g}}$, and the following expression was obtained:

$$
D_{v .5 e}^{-1}=k_{e} W_{g}^{n}
$$

Values of the proportionality constant $\mathrm{k}$ and exponent n are given in Table $\amalg$. At an atomizing-gas temperature of $293 \mathrm{~K}$, the following expression was obtained: $\mathrm{D}_{\mathrm{v} .5 \mathrm{e}}^{-1}=301 \mathrm{~W}_{\mathrm{g}}^{1.11}$, where $\mathrm{D}_{\mathrm{v} .5 \mathrm{e}}^{-1}$ and $\mathrm{W}_{\mathrm{g}}$ are expressed as $\mathrm{cm}^{-1}$ and $\mathrm{g} / \mathrm{sec}$, respectively.

The exponent 1.11 for $\mathrm{W}_{\mathrm{g}}$ is considerably less than 1.33 as predicted by theory for liquid-jet breakup in high-velocity gasflow. This discrepancy can be attributed to a loss of small vaporizing $\mathrm{LN}_{2}$ drops before spray measurements could be made with the scatteredlight scanner. In the present study, results agree better with atomization theory than those reported in Ref. 9. This is due to the allowance made in the present study for the effect of droplet vaporization on dropsize measurements of highly volatile sprays. This effect was not accounted for in Ref. 9 and although the dropsize data did appear to agree with theory, the proportionality constant $\mathrm{k}$ was too low to adequately characterize the initial unvaporized spray. Thus, the study in Ref. 9 did not take into account the effect of small droplets vaporizing completely before they could pass through the laser beam.

\section{Acceleration of $\mathrm{LN}_{2}$ Droplets}

The effect of droplet vaporization rate on experimental values of $D_{v .5 e}$ was determined by calculating vaporization time, $t$, as based on droplet velocity $V_{d}$, for $D_{v .5 e}$. Time, $t$, was calculated over a distance of $2.2 \mathrm{~cm}$, i.e., the distance from nozzle orifice to the downstream edge of the laser beam, as shown in Fig. 3.

In order to determine volume-median drop velocity, $\mathrm{V}_{\mathrm{d}}$, the acceleration, a, of $\mathrm{LN}_{2}$ droplets was calculated from the following momentum balance as given in Ref. 8:

$$
\mathrm{m}_{\mathrm{d}^{\mathrm{a}}}=\frac{1}{2} \rho_{\mathrm{g}} \mathrm{A}_{\mathrm{d}}\left(\mathrm{V}_{\mathrm{g}}-\mathrm{V}_{\mathrm{d}}\right)^{2} \mathrm{C}_{\mathrm{d}}
$$

where $m_{d}$ and $A_{d}$ are mass and area of dropsize $D_{v .5 e}$ respectively, i.e., $m_{d}=\rho_{1} \pi D_{v .5 e}^{3} / 6, C_{d}$ is the drag coefficient based on characteristic length, $D_{v .5}$. Rewriting this expression, in terms of change in drop-velocity squared, $\Delta \mathrm{V}_{\mathrm{d}}^{2}$, over the distance of travel, $\Delta \mathrm{x}$, the following relationship is obtained:

$$
\frac{\Delta \mathrm{V}_{\mathrm{d}}^{2}}{\Delta \mathrm{x}}=\frac{3 \rho_{\mathrm{g}}\left(\mathrm{V}_{\mathrm{g}}-\mathrm{V}_{\mathrm{d}}\right)^{2}}{2 \rho_{1} \mathrm{D}_{\mathrm{v} .5 \mathrm{e}}} \mathrm{C}_{\mathrm{d}}
$$

where $C_{d}=27 R^{0.84}$, as given in Ref. 8 , and $R e$ is based on the characteristic dropsize, $\mathrm{D}_{\mathbf{v} .5 \mathrm{e}}$.

The deceleration of atomizing gaseous nitrogen jets into a surrounding low velocity airflow was determined as follows. At the nozzle orifice, gas velocity, $V_{g}$, was equal to the acoustic velocity, $V_{c}$, of gaseous nitrogen. Values of $V_{g}$ used to solve Eq. (3), were calculated at downstream distances of $\mathrm{x}=0.5$, and $10 \mathrm{~cm}$, respectively and plotted in Fig. 5. Calculated values of $\mathrm{V}_{\mathrm{g}}^{2}$ are based on data given in Ref. 13 and plotted in Fig. 5 for comparison. The percent deceleration of the atomizing nitrogen gas is assumed to be approximately the same in both cases, since the two-fluid nozzles used in Ref. 13 and the present study were very similar in design.

To determine the acceleration of $\mathrm{LN}_{2}$ droplets characterized by $D_{v .5 e}$, values of $V_{d}^{2}$ were calculated by numerically integrating Eq. (3) and plotting $V_{d}^{2}$ against 
downstream distance, $\mathrm{x}$, as shown in Fig. 6, for three atomizing-gas temperatures. $\mathrm{LN}_{2}$ droplet vaporization time, $\Delta t$, was calculated from this plot by means of the expression $\Delta t=\Delta x / \nabla_{d}$. Calculated values of $\Delta t$ for a given distance $\Delta \mathrm{x}$ are given in Table III along with calculated Reynolds numbers averaged over the incremental distance $\Delta x$ and values of $D_{v \cdot 5 c}$. Gas and liquid transport properties used in calculating vaporization times are given in Table IV.

\section{Cryogenic Spray Vaporization Rates}

Vaporization rates of $\mathrm{LN}_{2}$ sprays characterized by $\mathrm{D}_{\mathrm{v} .5 \mathrm{e}}$ were calculated by using the following heatbalance equation: $\mathrm{dm}_{\mathrm{d}} / \mathrm{dt}=\mathrm{hA} \Delta \mathrm{T} / \mathrm{H}_{\mathrm{t}}$, where $\mathrm{h}$ is the heat-transfer coefficient, $\mathbf{A}$ is droplet surface-area based on $\mathrm{D}_{\mathrm{v} .5 \mathrm{e}}, \Delta \mathrm{T}=\mathrm{T}_{\mathrm{g}}-\mathrm{T}_{\mathrm{d}}$, and $\mathrm{H}_{\mathrm{t}}=\mathrm{H}_{\mathrm{v}}+\mathrm{C}_{\mathrm{p}} \Delta \mathrm{T}$. Here $\mathrm{H}_{\mathrm{v}}$ is the latent heat of vaporization of $\mathrm{LN}_{2}$ and $\mathrm{C}_{\mathrm{p}}$ is the specific heat of $\mathrm{GN}_{2}$. This expression may be rewritten as follows to obtain vaporization rate in terms of changes in droplet surface-area with time:

$$
\frac{\Delta \mathrm{D}_{\mathrm{v} .5}^{2}}{\Delta \mathrm{t}}=\frac{4 \mathrm{k}_{\mathrm{g}} \Delta \mathrm{TNu}}{\rho_{1} \mathrm{H}_{\mathrm{t}}}
$$

where $\mathrm{k}_{\mathrm{g}}$ and $\rho_{1}$ are gas thermal conductivity and liquid density, respectively. In previous fuel droplet studies reported in Ref. 8, a high-speed droplet tracking camera was used to determine vaporization rates of fuels such as n-octane, jet-A, and numerous other liquids including water, benzene, acetone, and carbon tetrachloride. It was found that: $\mathrm{Nu}=2+0.303 \mathrm{Re}^{0.6}$, where $\mathrm{Re}$ $=\rho_{\mathrm{g}} \mathrm{D}_{\mathrm{v} .5 \mathrm{e}} \Delta \mathrm{V} / \mu_{\mathrm{g}}$, and $\Delta \mathrm{V}$ is the average velocity difference over an incremental distance $\Delta \mathbf{x}$. Vaporization rate calculations were based on the characteristic drop diameter $\mathrm{D}_{\mathrm{v} .5 \mathrm{e}} \cdot \mathrm{GN}_{2}$ viscosity and thermal conductivity were evaluated at the average gas-film temperature, i.e., $\mathrm{T}_{\mathrm{f}}=1 / 2\left(\mathrm{~T}_{\mathrm{g}}+\mathrm{T}_{1}\right) \cdot \mathrm{LN}_{2}$ droplet surface temperatures were assumed to be near the boiling point, $77 \mathrm{~K}$, when droplet sprays were being accelerated and partially vaporized. The latent heat of vaporization of $\mathrm{LN}_{2}$ was evaluated at $77 \mathrm{~K}$ and the specific heat of nitrogen vapor was evaluated at the average gas-film temperature, $\mathrm{T}_{\mathrm{f}}$.

Experimental values of $\mathrm{D}_{\mathrm{v} .5 \mathrm{e}}^{-1}$, calculated values of $D_{v .5 c}^{-1}$ and changes in characteristic drop diameter squared, $\Delta \mathrm{D}_{\mathrm{v} .5}^{2}$, that occurred due to partial vaporization of the cryogenic sprays are given in Table V. Calculations were based on $\mathrm{GN}_{2}$ and $\mathrm{LN}_{2}$ flowrates of 4.54 and $51 \mathrm{~g} / \mathrm{sec}$, respectively. Values of $D_{v .5 c}$ were calculated from the expression: $-\Delta D_{\mathrm{v} .5}^{2}=D_{\mathrm{v} .5 \mathrm{c}}^{2}-\mathrm{D}_{\mathrm{v} .5 \mathrm{e}}^{2}$ and they are plotted against $\mathrm{W}_{\mathrm{g}}$ as shown in Fig. 7 .
From this plot, the following correlating expression is obtained: $D_{v \cdot 5 c}^{-1}=k_{c} W_{g}^{n}$, which is similar to Eq. (1). Values of $k_{c}$ and $n$ are given in Table $V$. For the case $T_{g}$ $=293 \mathrm{~K}$.

$$
D_{v .5 c}^{-1}=285 W_{g}^{1.33}
$$

Comparing this expression with Eq. (1), i.e., $D_{v}^{-1} \cdot 5 e$ $=301 \mathrm{~W}_{\mathrm{g}}^{1.11}$, shows that the proportionality constants $\mathrm{k}_{\mathrm{e}}$ and $\mathrm{k}_{\mathrm{c}}$ are nearly equal. Also, Eq. (5) shows that droplet vaporization did have considerable effect on the exponent $n$. The value of $n$ given in Eq. (5) agrees well with atomization theory which predicts $n=1.33$. Thus, the agreement of Eq. (5) with atomization theory indicates that an expresson for the unvaporized spray near the fuel-nozzle orifice can be calculated using heat-transfer and drag coefficients given in Ref. 8.

\section{Correlation of $\mathrm{D}_{\mathrm{v} .5 \mathrm{c}}$ with Dimensionless Force Ratios}

The calculated volume-median diameter $D_{\mathrm{v} .5 \mathrm{c}}$ was normalized with respect to $\mathrm{LN}_{2}$ jet diameter, $\mathrm{D}_{0}$, and as shown in Fig. 8, is plotted against the product of We, Re, and $\rho_{\mathrm{g}} / \rho_{1}$, i.e., the Weber number, Reynolds number, and gas-to-liquid density ratio, respectively. From this plot, the following dimensionless expression was derived:

$$
\frac{\mathrm{D}_{\mathrm{o}}}{\mathrm{D}_{\mathrm{v} .5 \mathrm{c}}}=\mathrm{k}_{\mathrm{c}}^{\prime}\left(\operatorname{WeRe} \frac{\rho_{\mathrm{g}}}{\rho_{1}}\right)^{0.44}
$$

where WeRe is the ratio of aerodynamic to liquid-jet surface forces, i.e., liquid viscosity and surface tension. From the three plots shown in Fig. 8, it is evident that $D_{v .5 c}$ is a function of atomizing-gas temperature, i.e., $D_{o} / D_{v .5 c}=f\left(T_{g}\right)$. Thus, $k_{c}^{\prime}$ is assumed to be a function of atomizing-gas temperature normalized with respect to $T_{f}$, i.e., $k_{c}^{\prime} \sim T_{g} / T_{f}$, where $T_{f}$ is the free-airstream temperature, $293 \mathrm{~K}$, of the low velocity airflow in the test section as shown in Fig. 1.

From a $\log -\log$ plot of $k_{c}^{\prime}$ against $T_{g} / T_{f}$, it was found that $k_{c}^{\prime} \sim\left(T_{g} / T_{f}\right)^{1.25}$ and as a result, the following correlating expression can be written:

$$
\frac{\mathrm{D}_{\mathrm{o}}}{\mathrm{D}_{\mathrm{v} .5 \mathrm{c}}}=\mathrm{k}_{\mathrm{c}}^{\prime \prime}\left(\mathrm{WeRe} \frac{\rho_{\mathrm{g}}}{\rho_{1}}\right)^{0.44}\left(\frac{\mathrm{T}_{\mathrm{g}}}{\mathrm{T}_{\mathrm{f}}}\right)^{1.25}
$$

This expression is plotted in Fig. 9 which shows that $\mathrm{k}_{\mathrm{c}}^{\prime \prime}$ $=9.0$. Thus, Eq. (7) may be rewritten as follows: 


$$
\mathrm{D}_{\mathrm{v} .5 \mathrm{c}}^{-1}=\frac{9}{\mathrm{D}_{\mathrm{o}}}\left(\frac{\mathrm{D}_{\circ}^{2}}{\rho_{1} \mu_{1} \sigma}\right)^{0.44}\left(\rho_{\mathrm{g}} \mathrm{V}_{\mathrm{c}}\right)^{1.33}\left(\frac{\mathrm{T}_{\mathrm{g}}}{\mathrm{T}_{\mathrm{f}}}\right)^{1.25}
$$

where $\rho_{\mathrm{g}} \mathrm{V}_{\mathrm{c}}=\mathrm{W}_{\mathrm{g}} / \mathrm{A}_{\mathrm{o}}$. Here it is evident that the thermodynamic effect of normalized atomizing-gas temperature, $T_{g} / T_{f}$ on the reciprocal volume-median diameter is nearly as great as that of the atomizing-gas mass flux $\rho_{\mathrm{g}} \mathrm{V}_{\mathrm{c}}$, which is also a function of gas temperature, i.e., $\rho_{\mathrm{g}} \mathrm{V}_{\mathrm{c}} \sim \mathrm{T}_{\mathrm{g}}^{-0.5}$. As a result, Eq. (8) shows that $\mathrm{D}_{\mathrm{v} .5 \mathrm{c}}^{-1}$ $\sim \mathrm{T}_{\mathrm{g}}^{0.58}$. A similar effect of atomizing-gas temperature on $\mathrm{D}_{\mathrm{v} .5}$ was obtained for water sprays, as reported in Ref. 15.

From experimental dropsize measurements of partially vaporized liquid-nitrogen sprays, it was found that increasing the atomizing-gas temperature gave a marked increase in the surface area per unit volume of liquid-nitrogen sprays. A result that would be very beneficial in producing very rapid and efficient fuelspray combustion in gas turbine and rocket combustors.

\section{Concluding Remarks}

Computations in the present study were based on numerical integration of momentum and heat-transfer expressions that had been developed in previous droplet studies, at NASA Lewis. As a result, the effect of droplet vaporization on dropsize measurements was determined. Without this source of knowledge, on calculating rates of heat and momentum transfer to vaporizing cryogenic drops, it would be almost impossible to determine the characteristic dropsize of an initially unvaporized cryogenic spray produced at the orifice of a two-fluid fuel nozzle. Thus with the computational method used in this study, it was possible to determine the effect of atomizing-gas temperature on cryogenic spray dropsize, once the effect of droplet vaporization on dropsize measurements had been determined. Also, it was found that the effect of atomizing-gas mass-flux, $\rho_{\mathrm{g}} \mathrm{V}_{\mathrm{c}}$, on volume-median drop diameter agreed well with atomization theory for liquid-jet breakup in high-velocity gasflows. The final correlating expression derived in this study (Eq. (8)), can be readily applied to analytical modeling of fuel spray vaporization and combustion in gas-turbine and rocket combustors, within the range of variables investigated in this study.

\section{$\underline{\text { References }}$}

1. Ingebo, R.D., "Experimental and Theoretical Effects of Nitrogen Gas Flowrate on Liquid Jet
Atomization," Journal of Propulsion and Power, Vol. 4, No. 6, Nov.-Dec. 1988, pp. 406-411.

2. Ingebo, R.D., "Effect of Vaporization on Cryogenic Spray Dropsize Measurements, NASA TM-105909, 1992. (Also AIAA Paper 93-0692, 1992.)

3. Kim, K.Y., and Marshall, W.R., Jr., "Drop Distributions from Pneumatic Atomizers," AIChE Journal, Vol. 17, No. 3, May 1971, pp. 575-584.

4. Lorenzetto, G.E., and Lefebvre, A.H., "Measurements of Drop Size on a Plain-Jet Airblast Atomizer," AIAA Journal, Vol. 15, No. 7, July 1977, pp. 1006-1010.

5. Nukiyama, S., and Tanasawa, Y., "Experiments on the Atomization of Liquids by Means of a Air Stream, Parts III-IV," Transactions of the Society of Mechanical Engineers, Japan, Vol. 5, No. 18, Feb. 1939, pp. 63-75.

6. Weiss, M.A., and Worsham, C.H., "Atomization in High Velocity Airstreams," American Rocket Society Journal, Vol. 29, No. 4, Apr. 1959, pp. 252-259.

7. Wolf, H.E., and Andersen, W.H., "Aerodynamic Break-up of Liquid Drops, " Proceedings of the 5th International Shock Tube Symposium, edited by Z.I. Slawasky, J.F. Moulton, Jr., and W.S. Filler, Naval Ordnance Lab., White Oak, MD, 1966, pp. 1145-1169. (Avail. NTIS, AD-638011.)

8. Ingebo, R.D., "Atomization, Acceleration and Vaporization of Liquid Fuels," Sixth Symposium (International) on Combustion, Reinhold Publishing Corporation, New York, 1957, pp. 684-687.

9. Ingebo, R.D., and Buchele, D.R., "Scattered-Light Scanner Measurements of Cryogenic Liquid-Jet Breakup, ${ }^{\prime}$ NASA TM-102432, 1990.

10. Swithenbank, J., Beer, J.M., Taylor, D.S., Abbot, D., and McCreath, G.C., "A Laser Diagnostic Technique for the Measurement of Droplet and Particle Size Distribution," Experimental Diagnostics in Gas Phase Combustion Systems, edited by B.T. Zinn and C.T. Bowman, Progress in Astronautics and Aeronautics, Vol. 53, AIAA, New York, 1977, pp. 421-447.

11. Buchele, D.R., "Particle Sizing by Weighted Measurements of Scattered Light," NASA TM-100968, 1988. 
12. Felton, P.G., Hamidi, A.A., and Aigal, A.K., "Measurement of Drop-Size Distribution in Dense Sprays by Laser Diffraction, ${ }^{n}$ from No. 12: ICLASS- 86 ; Proceedings of the Third International Conference on Liquid Atomization and Spray Systems, Vol. 2, edited by P. Eisenklam and A. Yule, Institute of Energy, London, UK, 1985, pp. IVA/4/1-IVA/4/11.

13. Bulzan, D.L., Levy, Y., Aggarwal, S.K., and Chitre, S., "Measurements and Predictions of a
Liquid Spray From an Air-Assist Nozzle," Atomization and Sprays, vol. 2, 1992, pp. 445-462.

14. Adelberg, M., "Mean Drop Size Resulting From The Injection of a Liquid Jet Into a High Speed Gas Stream," AIAA Journal, Vol. 6, No. 6, June 1986, pp. 1143-1147.

15. Ingebo, R.D., "Spray Measurements of Aerothermodynamic Effect on Disintegrating Liquid Jets," NASA TM-104501, 1991.

TABLE I.-ATOMIZING-GAS VELOCITY EXPO-

NENT, n, FOR HIGH-VELOCITY GASFLOW

BREAKUP OF LIQUID JETS

\begin{tabular}{|c|c|}
\hline Source & $\begin{array}{c}\text { Exponent, } \\
\mathbf{n}\end{array}$ \\
\hline Adelberg, Theory ${ }^{14}$ & 1.33 \\
\hline Present study, $x=2.2 \mathrm{~cm}$ & 1.33 \\
\hline Kim and Marshall ${ }^{3}$ & 1.14 \\
\hline Lorenzetto and Lefebvre & 1.00 \\
\hline Nukiyama and Tanasawa, ${ }^{5} x=5$ to $25 \mathrm{~cm}$ & 1.00 \\
\hline Weiss and Worsham ${ }^{6}$ & 1.33 \\
\hline Wolf and Anderson ${ }^{7}$ & 1.33 \\
\hline
\end{tabular}

TABLE II.-COEFFICIENT $k$

AND EXPONENT n FOR

EQ. (1) ${ }^{2}$

\begin{tabular}{|c|c|c|}
\hline $\begin{array}{c}\text { Atomizing-gas } \\
\text { temperature, } \\
\mathrm{T}_{\mathbf{g}},\end{array}$ & $\mathbf{k}$ & $\mathbf{n}$ \\
$\mathrm{K}$ & & \\
\hline 111 & 82 & 1.22 \\
293 & 301 & 1.11 \\
422 & 367 & 1.08 \\
\hline
\end{tabular}

${ }^{\mathrm{a}} \mathrm{D}_{\mathrm{v} \cdot \mathrm{Se}_{\mathrm{e}}^{-1}}^{-1} \mathrm{k}_{\mathrm{e}} \mathrm{W}_{\mathrm{g}}^{\mathrm{n}}$

TABLE III.-VAPORIZATION TIME, $t$, FOR $D_{v .5 e}^{-1} A_{\text {T }} W_{g}=4.54 \mathrm{~g} / \mathrm{sec}$ AND

$\Delta \mathrm{x}=2.2 \mathrm{~cm}$

\begin{tabular}{|c|c|c|}
\hline \multicolumn{2}{|c|}{$\Delta \mathrm{x}=2.2 \mathrm{~cm}$} \\
$\begin{array}{c}\text { Atomizing-gas } \\
\text { temperature, } \\
\mathrm{T}_{\mathrm{g}},\end{array}$ & $\mathrm{D}_{\mathrm{v} .5 \mathrm{e}^{9}}^{-1}$ & $\begin{array}{c}\Delta \mathrm{t} \times 10^{4} \\
\mathrm{sec}\end{array}$ \\
$\mathrm{K}$ & $\mathrm{cm}^{-1}$ & \\
\hline 111 & 540 & 4.40 \\
293 & 1600 & 1.44 \\
422 & 1900 & .99 \\
\hline
\end{tabular}


TABLE IV.- $\mathrm{GN}_{2}$ AND $\mathrm{LN}_{2}$ TRANSPORT PROPERTIES AT

$\mathrm{W}_{\mathrm{g}}=4.54 \mathrm{~g} / \mathrm{sec}$ AND $\mathrm{T}_{\mathrm{g}}=293 \mathrm{~K}$

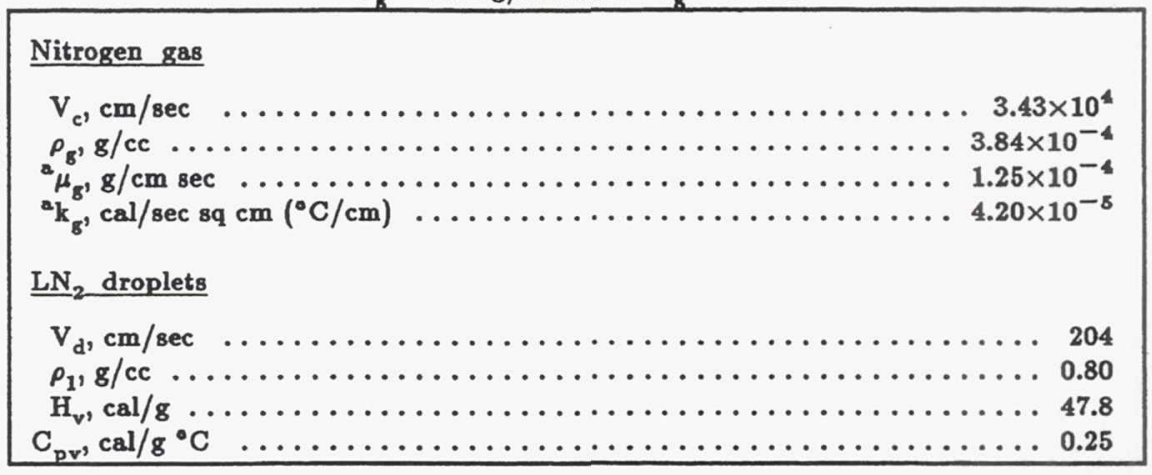

${ }^{a}$ Evaluated at $T_{f}=1 / 2\left(T_{g}-T_{1}\right)$.

TABLE V.-REDUCTION IN DROPSIZE, $-\Delta D_{v .5}^{2}$, AND UNVAPORIZED DROPSIZE, $D_{\mathrm{v} .5}, A T \mathrm{~W}_{\mathrm{g}}=4.54 \mathrm{~g} / \mathrm{sec}$

\begin{tabular}{|c|c|c|c|}
\hline $\begin{array}{c}\text { Atomizing-gas } \\
\text { temperature, } \\
\mathrm{T}_{\mathrm{g}},\end{array}$ & $\begin{array}{c}-\Delta \mathrm{D}_{\mathrm{v} . \mathrm{s}^{2} \times 10^{9},}^{\mathrm{cm}^{2}} \\
\mathrm{~K}\end{array}$ & $\begin{array}{c}\mathrm{D}_{\mathrm{v} .8 \mathrm{e}}^{-1}, \\
\mathrm{~cm}^{-1}\end{array}$ & $\begin{array}{c}\mathrm{D}_{\mathrm{v} .8 \mathrm{c}}^{-1} \\
\mathrm{~cm}^{-1}\end{array}$ \\
\hline 111 & 29.7 & 540 & 565 \\
293 & 16.3 & 1600 & 2100 \\
422 & 13.2 & 2000 & 2950 \\
\hline
\end{tabular}

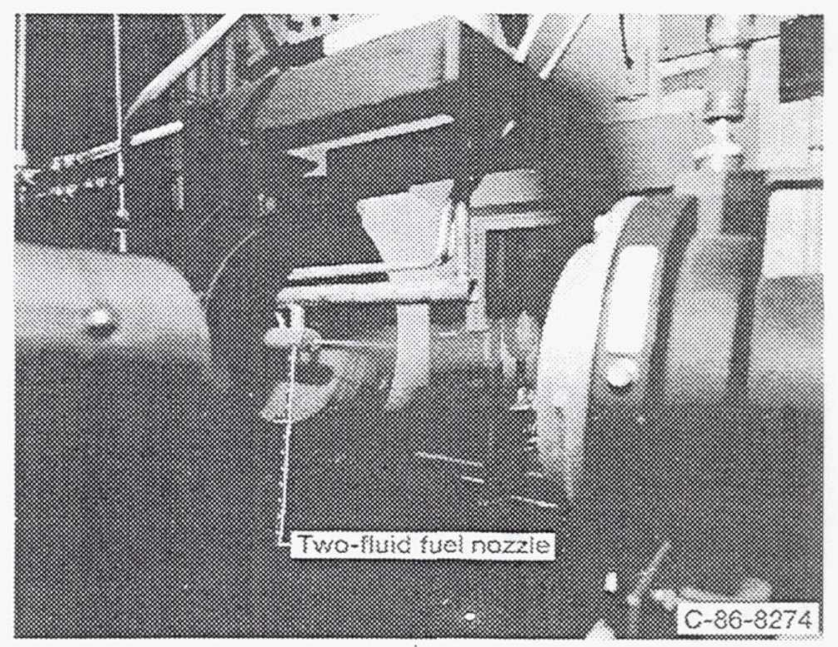

Figure 1.-Apparatus and auxilliary equipment. 


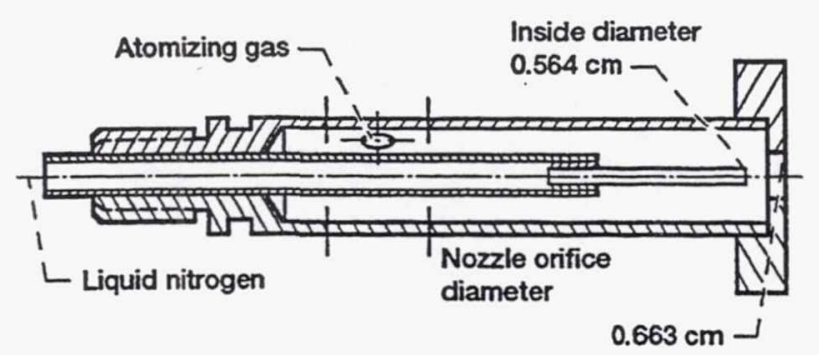

Figure 2-Diagram of pneumatic two-fluid atomizer.

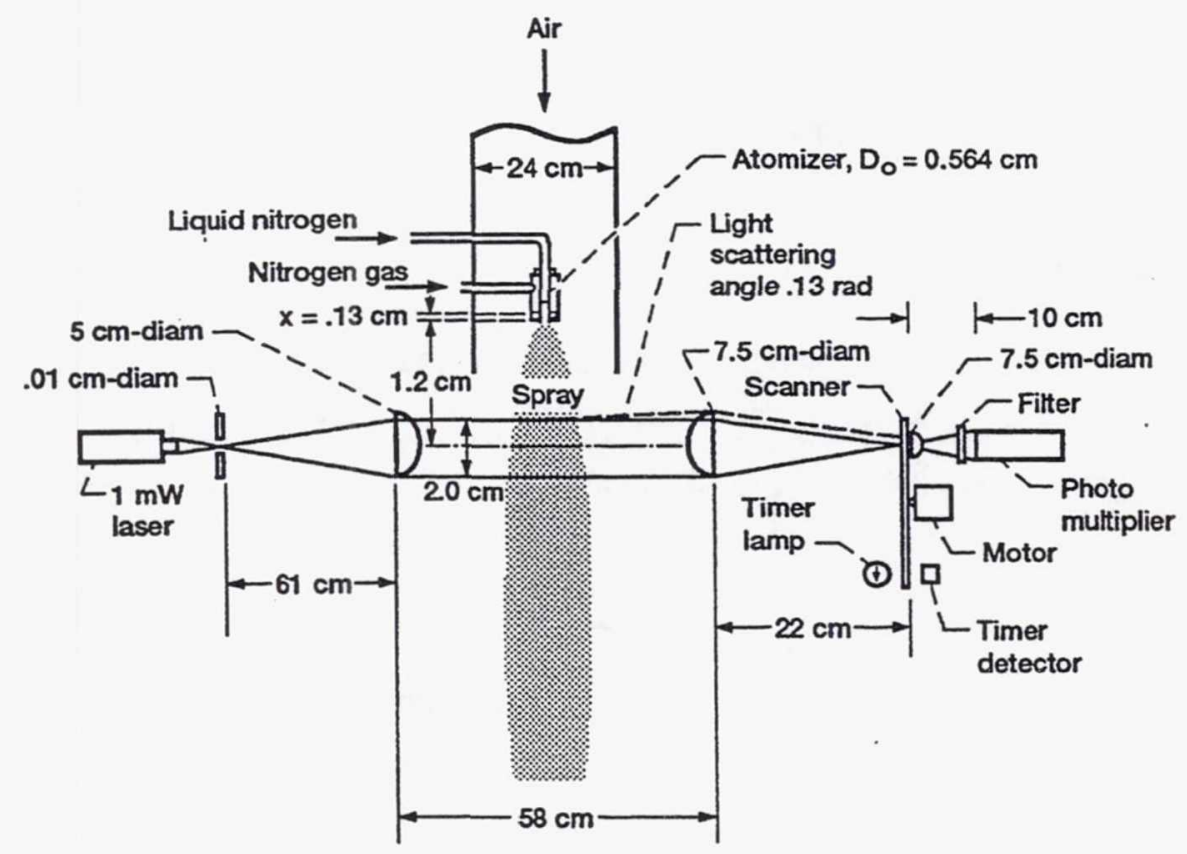

Figure 3.-Atmospheric pressure test section and optical path of scattered-light scanner.

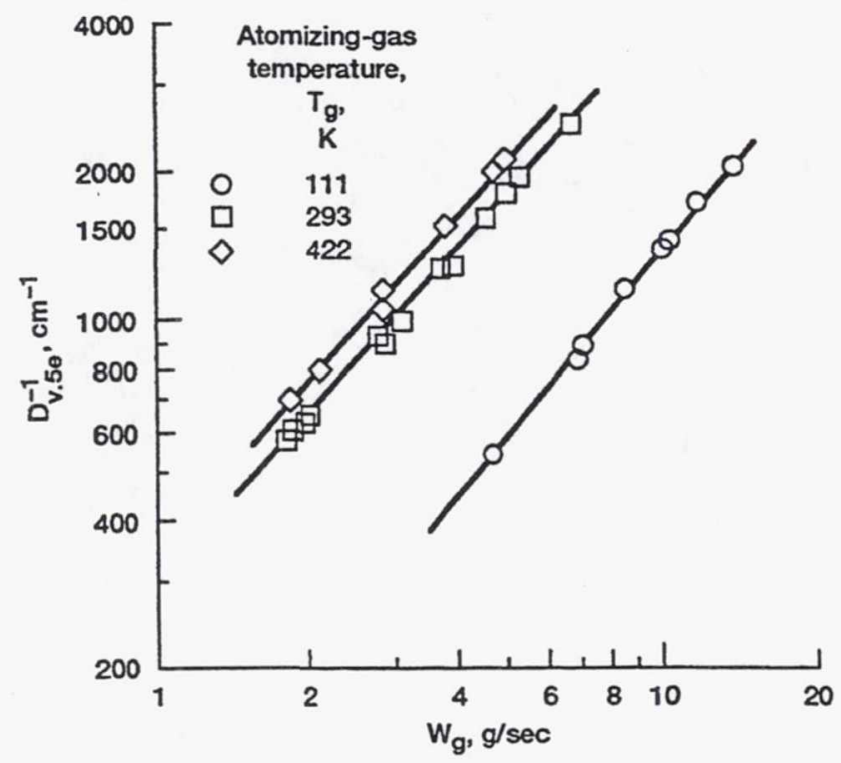

Figure 4.-Effect of atomizing-gas flowrate on reciprocal volumemedian diameter, $\mathrm{D}_{\mathrm{v} .5 \mathrm{e}}^{-1}$, for partially vaporized $\mathrm{LN}_{2}$ sprays. 


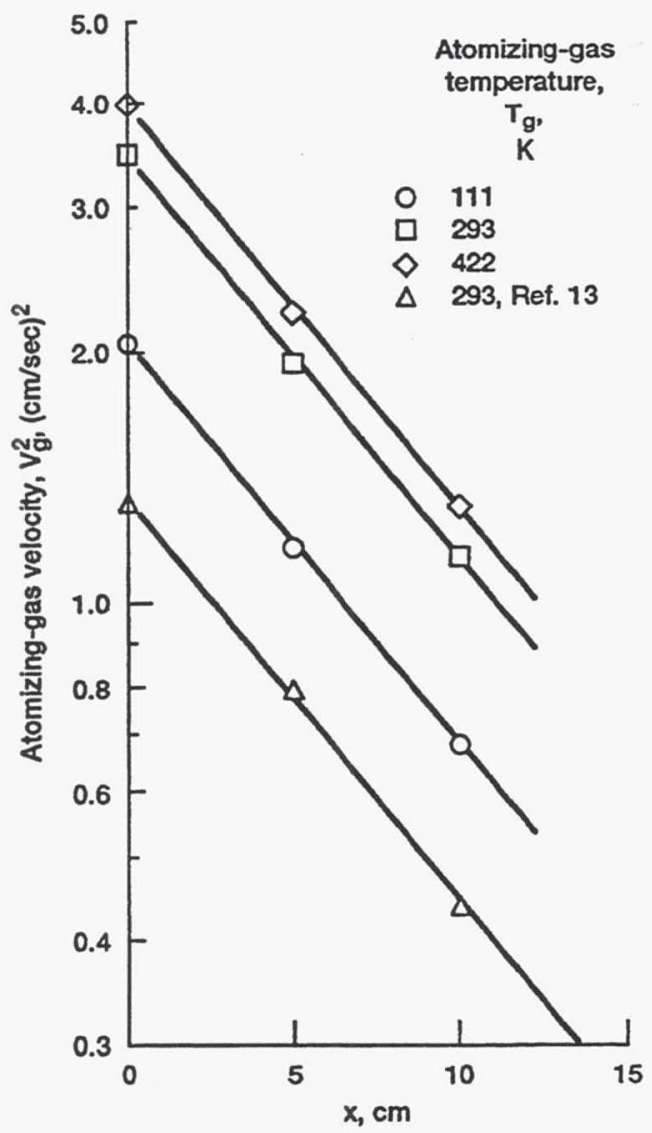

Figure 5.-Deceleration of atomizing-gas, $\mathrm{GN}_{2}$, downstream of fuel-nozzle orifice.
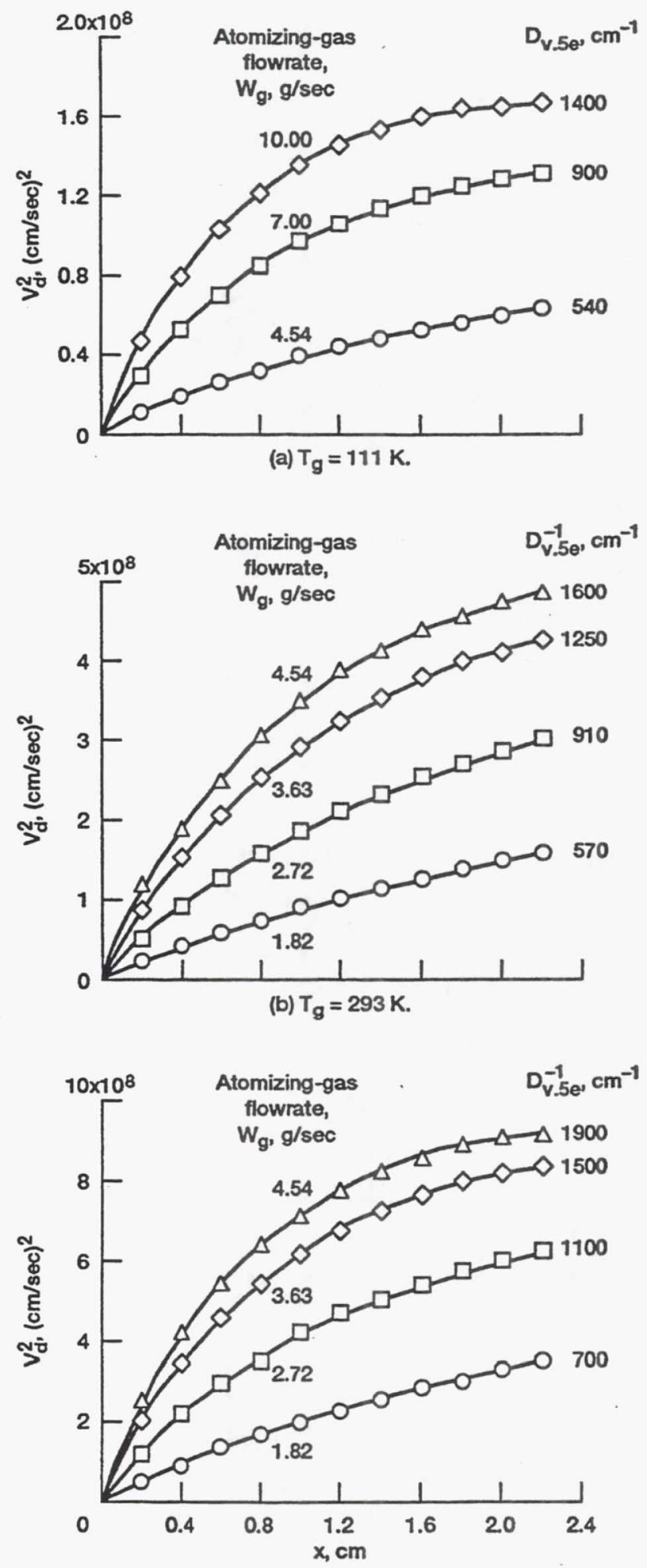

(c) $\mathrm{T}_{\mathrm{g}}=422 \mathrm{~K}$.

Figure 6.-Acceleration of volume-median dropsize, $D_{v .5 e}$. 


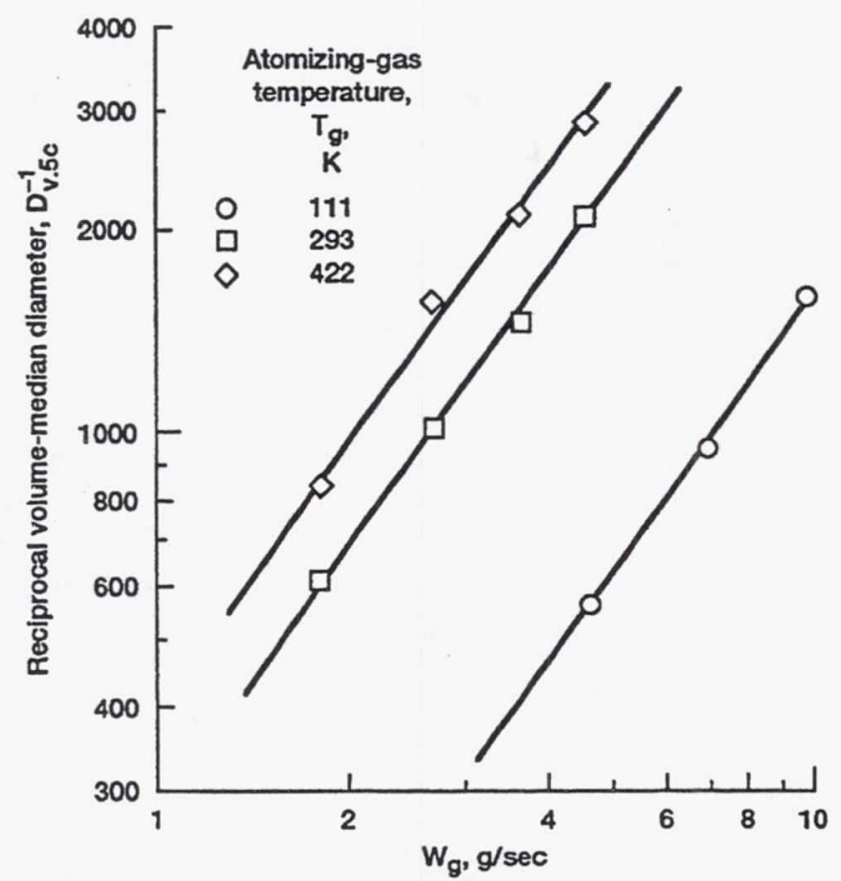

Figure 7.-Calculated effect of $\mathrm{Wg}$ on initial unvaporized value of $D_{\mathrm{v} .5 \mathrm{c}}$, at fuel nozzle orifice, $\mathrm{x}=0$.

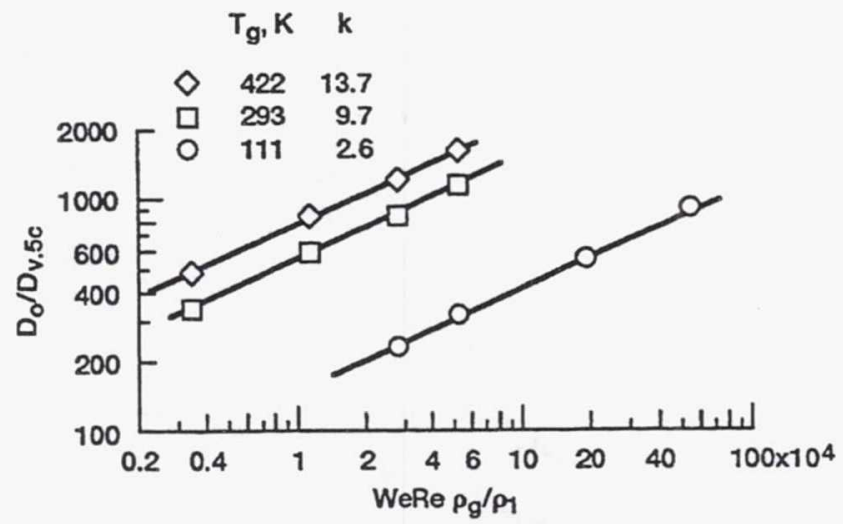

Figure 8.-Correlation of $D_{\alpha} / D_{v .5 c}$ with dimensionless groups.

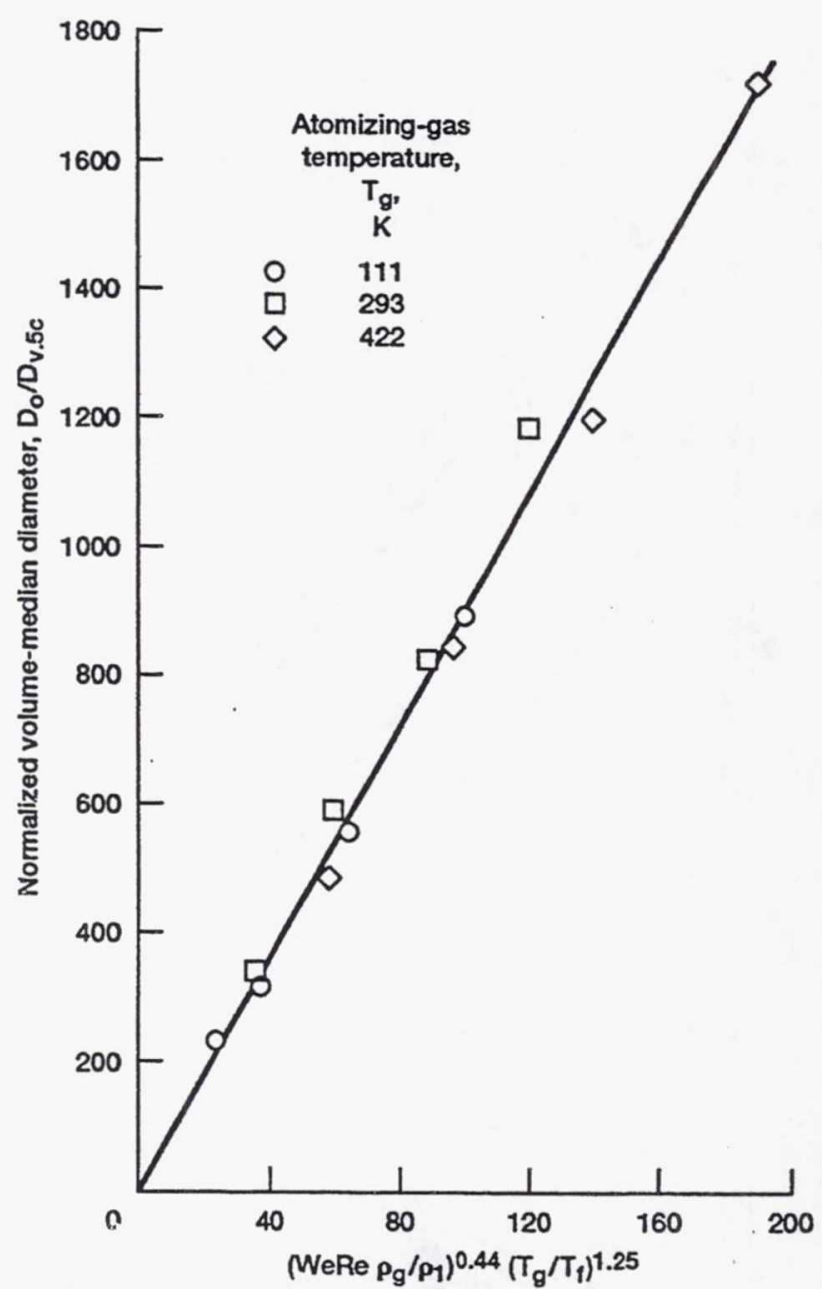

Figure 9.-Correlation of $D_{o} / D_{v .5 c}$ with dimensionless groups. 
Public reporting burden for this collection of information is estimated to average 1 hour per response, including the time for reviewing instructions, searching existing data sources, gathering and maintaining the data needed, and completing and reviewing the collection of information. Send comments regarding this burden estimate or any other aspect of this collection of information, including suggestions for reducing this burden, to Washington Headquarters Services, Directorate for information Operations and Reports, 1215 Jefferson Davis Highway, Suite 1204, Arlington, VA 22202-4302, and to the Office of Management and Budget, Paperwork Reduction Project (0704-0188), Washington, DC 20503.

\begin{tabular}{|l|c|c|}
\hline 1. AGENCY USE ONLY (Leave blank) & $\begin{array}{c}\text { 2. REPORT DATE } \\
\text { June } 1993\end{array}$ & $\begin{array}{r}\text { 3. REPORT TYPE AND DATES COVERED } \\
\text { Technical Memorandum }\end{array}$ \\
\hline
\end{tabular}

\section{TITLE AND SUBTITLE}

Atomizing-Gas Temperature Effect on Cryogenic Spray Dropsize

6. AUTHOR(S)

Robert D. Ingebo
5. FUNDING NUMBERS

WU-505-62-52

8. PERFORMING ORGANIZATION REPORT NUMBER

E-7754

National Aeronautics and Space Administration

Lewis Research Center

Cleveland, Ohio 44135-3191

0. SPONSORING/MONITORING AGENCY REPORT NUMBER

National Aeronautics and Space Administration

Washington, D.C. 20546-0001

NASA TM-106106

\section{SUPPLEMENTARY NOTES}

Prepared for the 29th Joint Propulsion Conference and Exhibit cosponsored by the AIAA, SAE, ASME, and ASEE, Monterey, California, June 28-30, 1993. Responsible person, Robert D. Ingebo, (216) 433-3586.

\section{2a. DISTRIBUTION/AVAILABILITY STATEMENT}

12b. DISTRIBUTION CODE

Unclassified - Unlimited

Subject Category 35

13. ABSTRACT (Maximum 200 words)

Correlating expressions for two-phase flow breakup of liquid nitrogen, $\mathrm{LN}_{2}$, jets in sonic velocity nitrogen gasflows were obtained for an atomizing-gas temperature range of 111 to $442 \mathrm{~K}$. The correlations were based on characteristic dropsize measurements obtained with a scattered-light scanner. The effect of droplet vaporization on the measurements of the volume-median dropsize, $\mathrm{D}_{\mathrm{v} .5}$, was calculated by using previously determined heat and momentum transfer expressions for droplets evaporating in high-velocity gasflow. Finally, the dropsize of the originally unvaporized spray, $\mathrm{D}_{\mathrm{v} .5 \mathrm{c}}$, was calculated, normalized with respect to jet diameter, $\mathrm{D}_{\mathrm{O}}$, and correlated with atomizing-gas flowrate and temperature, according to the following expression:

$$
\mathrm{D}_{\mathrm{o}} / \mathrm{D}_{\mathrm{v} .5 \mathrm{c}}=9.0\left(\mathrm{WeRe} \rho_{\mathrm{g}} / \rho_{1}\right)^{0.44}\left(\mathrm{~T}_{\mathrm{g}} / \mathrm{T}_{\mathrm{o}}\right)^{1.25}
$$

where $\mathrm{WeRe}=\rho_{\mathrm{g}} \dot{\mathrm{D}}_{\mathrm{o}}^{2} \mathrm{~V}_{\mathrm{o}}^{3} / \mu_{1} \sigma$. Here $\mu_{1}$ is liquid viscosity, $\rho_{\mathrm{g}}$ and $\rho_{1}$ are gas and liquid densities, respectively, $\sigma$ is surface tension, $\mathrm{V}_{\mathrm{c}}$ is acoustic gas velocity and $\mathrm{T}_{\mathrm{g}}$ is atomizing-gas temperature, normalized with respect to airstream temperature, $T_{0}=293 \mathrm{~K}$. This expression agrees well with atomization theory which predicts $D_{v .5} \sim V_{c}^{1.33}$, for liquid-jet breakup in high-velocity gasflow.

\section{SUBJECT TERMS}

Atomization; Vaporization; Fuel sprays; Dropsize correlations; Heat-transfer and drag coefficients; Cryogenic liquids

\begin{tabular}{|c|c|c|c|}
\hline $\begin{array}{c}\text { 17. SECURITY CLASSIFICATION } \\
\text { OF REPORT }\end{array}$ & $\begin{array}{c}\text { 18. SECURITY CLASSIFICATION } \\
\text { OF THIS PAGE } \\
\text { Unclassified }\end{array}$ & $\begin{array}{c}\text { 19. SECURITY CLASSIFICATION } \\
\text { OF ABSTRACT } \\
\text { Unclassified }\end{array}$ & \begin{tabular}{c} 
Unclassified \\
\hline
\end{tabular}
\end{tabular}

